\title{
Viability of homologous and heterologous subcutaneous transplantation of fresh germ cells in rabbits
}

Paula M.A. Cerialle ${ }^{1}$, Carlos G. Almodin ${ }^{1}$, Moacir R. M. Radaelli1,2, Vânia C. Minguetti-Câmara ${ }^{1}$, Michelle C. Souza ${ }^{2}$, Carlos A.M. Oliveira ${ }^{3}$, Antonio J. Gonçalves ${ }^{4}$

\author{
${ }^{1}$ Materbaby - Human Reproduction and Genetics, Maringá, Brazil \\ ${ }^{2}$ Ingá University Center- UNINGA, Maringá, Brazil \\ ${ }^{3}$ Núcleo Santista - Human Reproduction, Santos, Brazil \\ ${ }^{4}$ Surgery Department, Medical Sciences School at the Santa Casa de São Paulo Hospital, São Paulo, Brazil
}

\begin{abstract}
Objective: This study aimed to compare heterologous to homologous transplantation of fresh ovarian germ cells in rabbits.

Methods: Twelve female white New Zealand rabbits (Oryctolagus cuniculus) were randomly numbered and submitted to bilateral oophorectomies. The ovaries from the six odd-numbered rabbits were dissected and cortical germinal tissue was digested in collagenase type 1 to obtain six solutions containing stromal and germ cells, which were injected in the abdominal region of the odd-numbered rabbits themselves (homologous transplantation) and of the even-numbered rabbits (heterologous transplantation) off immunosuppression. Sixty days after transplantation, the tissue around the transplanted region was excised, processed and sent to histological analysis with hematoxylin-eosin staining and $\mathrm{Bcl}-2$ immunohistochemistry to verify the presence and viability of the transplanted cells.
\end{abstract}

Results: The analyzed specimens contained ovarian stroma, while follicular cells were found in $66.6 \%$ of the homologous and in $60 \%$ of the heterologous transplant specimens. Mild inflammatory reaction was observed in all heterologous specimens, and in only one $(16.7 \%)$ of the homologous specimens. However, this inflammatory reaction was not so intense as to cause the death of the implanted cells. Except for the specimens from rabbits 7 and 8 , all specimens were stained for $\mathrm{Bcl}-2$, indicating that most of them were viable.

Conclusions: The results of this study supported the viability of heterologous transplantation of fresh ovarian germ cells. However, more studies are required to further our understanding and improve the germ cell separation technique.

Keywords: Germ cells, transplantation, heterologous, rabbits

\section{INTRODUCTION}

In recent decades many women have opted to have children at a later age and, as a result, the number of infertile women has increased significantly. Moreover, one in every 250 women under the age of 35 suffer from primary ovarian failure (POF) and the consequences of this event (Aubard et al., 1998). In addition to fertility issues, women with POF also suffer from physical effects of hypoestrogenism such as vulvovaginal atrophy, decalcification, cardiovascular disease, and psycho-emotional disorders (De Vos et al., 2010; Wolff et al., 2013). Although several studies have been conducted to find appropriate solutions for this group of women (Bhavnani \& Stanczyk, 2014; Gaowa et al., 2015), medicine has not been able to find an effective solution to these problems.

Heterologous insemination, and the donation and reception of oocytes from different women have been successfully employed for more than two decades in routine infertility treatments in human reproduction centers all over the world (Cobo et al., 2015). Although oocyte donation is a possible solution to infertility, the only solution available at this point for the physical changes resulting from estrogen deprivation is hormone replacement therapy (Pinto Marín et al., 2011).

In an attempt to deal with infertility and the hormonal problems caused by POF, animal model studies have focused on the recovery of ovarian function by freezing ovarian germinal tissue for later reimplantation (Almodin et al., 2004a, 2004b). Based on these studies, the first live birth of a child after orthotopic autotransplantation of cryopreserved ovarian tissue was reported in 2004 (Donnez et al., 2004). Restoration of ovarian function and fertility, followed by the birth of a healthy baby, were also reported after the combined orthotopic and heterotopic transplantation of cryopreserved ovarian tissue in a 31-year-old woman previously treated for Hodgkin's disease (Demeestere et al., 2007). A recent review reported the outcomes of 60 orthotopic reimplantations of cryopreserved ovarian tissue performed by three groups of researchers, as well as 24 live births (Donnez et al., 2013).

Despite the success achieved with homologous transplantation of ovarian germinal tissue, this procedure is not an option for many women diagnosed with POF who, for different reasons, do not possess cryopreserved ovarian tissue. In theory, the transplantation of germinal tissue received from other women might benefit this group of patients. A recent study reported on ten monozygotic twins discordant for POF offered ovarian transplantation with fresh and cryopreserved tissue with successful pregnancies, with the oldest graft functioning for 36 months (Silber et al., 2008). These results suggest that heterologous transplantation may be viable.

Considering that rejection is not an issue in the transplantation of germ cells such as oocytes and sperm, it would seem logical to infer that the germ cells present in the ovary (stroma and follicles) would behave in a similar fashion. However, in an animal model study conducted with hens, the authors demonstrated that the fibroblastlike cells in the theca layer of primary follicles were positive for molecular histocompatibility complex class II (MHC-II), which is responsible for immunoreaction in the ovaries (Barua \& Yoshimura, 1999). Thus, if ovarian germ cells were separated from the MHC-II-positive fibroblasts present in the surrounding tissue, the probability of the germ cells being rejected in the host site would be minimized, enabling the heterologous transplantation of these cells.

Therefore, this study aimed to evaluate the viability of subcutaneous heterologous transplantation of fresh germ cells in rabbits versus homologous transplantation.

\section{MATERIALS AND METHODS}

\section{Ethics committee approval}

The Institutional Animal Care and Use Committee (IACUC) at Ingá University Center (UNINGA), Maringá, 
Brazil, approved this animal model study. The procedures performed in this study were carried out at the Animal Surgery facilities of UNINGA with the technical support of Materbaby - Human Reproduction and Genetics between February 2016 and May 2016. The procedures were carried out in accordance with the guidelines established by the Brazilian College of Animal Experimentation (COBEA).

\section{Animals}

The study population consisted of twelve female white New Zealand rabbits (Oryctolagus cuniculus) obtained from Central Animal Laboratory of the Medical School of the University of São Paulo, São Paulo, Brazil. With ages ranging between three and six months and weighing between 2.5 and $4 \mathrm{~kg}$, the rabbits were specifically raised for research purposes. The number of subjects used in this experiment was based on previous animal studies (Almodin et al., $2004,2004)$. None of the rabbits had physical anomalies, ectopic ovaries, ovarian malformations, or tumors, which might adversely impact study outcomes.

Each of the rabbits was placed in a standard individually identified polypropylene cage $(50 \times 30 \times 50 \mathrm{~cm})$ in the vivarium at UNINGA. They were kept at constant temperature (around $25^{\circ} \mathrm{C}$ ) on a 12-hour light/12-hour dark cycle for 40 days before the procedures were initiated to ensure they were fit for the experiment. The rabbits were given water and food proper for the species (Nuvilab CR1, Nuvital, Colombo, PR) ad libitum during their stay at the vivarium.

\section{Surgical Procedures}

The twelve rabbits were randomly numbered from 1 to 12 and identified by a tattoo on the inner portion of the right ear. Odd-numbered rabbits were assigned to the homologous transplantation group, while even-numbered rabbits were placed in the heterologous transplantation group.

The subjects were submitted to bilateral oophorectomies in pairs ( 1 and 2 etc.). On the day of surgery, food and water was withdrawn two hours before the procedure, and pre-anesthesia with acepromazine $0.2 \%(0.1 \mathrm{mg} /$ $\mathrm{kg}$ ) was performed $30 \mathrm{~min}$ before surgery to mitigate stress. Then, the rabbits were taken to the operating room, where they were administered general anesthesia with xylazine $2 \%(10 \mathrm{mg} / \mathrm{kg})$ and ketamine $10 \%(75 \mathrm{mg} /$ $\mathrm{kg}$ ) (Bayer, Leverkusen, Germany). Oxygen therapy (3l/ min) was maintained throughout the surgical procedure. The animals were considered anesthetized when they did not respond to handling and to susceptibility tests. The subjects were anesthetized by a veterinary physician specialized in animal anesthesia.

Both ovaries were surgically removed and placed in Petri dishes containing cold buffer solution with glucose and pyruvate supplemented with $10 \%$ synthetic serum PBS (Dubecco's Ingamed ${ }^{\circledR}$, Maringá, Brazil); the specimens were immediately sent to the reproduction laboratory. At the end of the procedure, the subjects were administered $0.2 \mathrm{mg} / \mathrm{kg}$ of meloxicam $(0.2 \mathrm{mg} / \mathrm{kg})$ as a long-term antiinflammatory agent ( 24 hours).

\section{Germ Cell Solution}

Once in the reproduction laboratory, the ovaries were longitudinally dissected with a scalpel; the medullar part was discarded, while the cortical layer was sectioned into small pieces (approximately $3 \mathrm{~mm}^{2}$ ). The germinal tissue fragments from the odd-numbered rabbits were digested in collagenase type 1 , following a protocol previously described with some modifications (Osterholzer et al., 1985): i) the ovarian tissue fragments were washed five times with PBS to remove blood and debris; ii) then the specimens were placed in $15-\mathrm{ml}$ centrifuge tubes with collagenase type 1
300IU/ml (Sigma- Aldrich, St. Louis, USA) diluted in PBS; iii) the solution was gently homogenized for 45 minutes to allow tissue digestion and the separation of germ cells; iv) the solution was centrifuged at $200 \mathrm{G}$ for 10 minutes; v) the supernatant was removed and the resulting precipitate was washed with PBS twice to remove residual collagenase; and vi) the precipitate was then diluted in $1.0 \mathrm{ml}$ of PBS. Six solutions were prepared, one for each odd-numbered rabbit.

\section{Germ Cell Transplantation}

Two insulin syringes equipped with $18 \mathrm{G}$ needles $(1.2 \mathrm{~mm}$ diameter) were prepared with $0.5 \mathrm{ml}$ of solution containing germ cells; the contents of one were injected in the donator odd-numbered rabbit (homologous transplantation) and the other on the subsequent evennumbered rabbit (heterologous transplantation). Before the injection, a sterile stainless steel marker $0.7 \mathrm{~mm}$ in diameter and $10 \mathrm{~mm}$ long was inserted into the distal end of the needle. The transplantations were performed as part of the same surgical procedure, approximately 75 minutes after the oophorectomy had been performed. The solution containing germ cells was injected subcutaneously, together with the metal marker, in the abdomen of the rabbits two centimeters below the bottom left nipple. After transplantation, the rabbits were returned to the vivarium and kept in the same room under the same conditions with ad libitum supply of food and water until the excisional biopsy.

\section{Transplanted Tissue Analysis}

Sixty days after transplantation, an excisional biopsy of approximately $2 \mathrm{~cm}$ in diameter was performed in each of the subjects in the subcutaneous tissue around the metallic marker; the specimens were sent to histological assessment and immunohistochemistry testing.

The slides stained with hematoxylin-eosin provided data for the histological assessment. The parameters studied were the presence of ovarian stroma, follicular cells, and signs of necrosis and inflammation.

Immunohistochemistry tests were performed with a marker for the oncogenic protein that inhibits apoptosis (BCl-2), which is found within the mitochondrial membrane, endoplasmic reticulum and nuclear envelope. Sections were incubated with primary antibodies (clone 124 - DAKO Corp., Carpinteria, CA) prepared in a previously optimized $\mathrm{BCl}-2$ solution. In order to allow the visualization of the reaction, the sections were treated with a chromogenic substrate (diaminobenzidine $60 \mathrm{mg} \%$ in PBS with $1.5 \mathrm{ml}$ of hydrogen peroxide $20 \mathrm{vol}$ ) for five minutes at $37^{\circ} \mathrm{C}$. The sections were counterstained with Harris hematoxylin (HHS128 - Sigma-Aldrich, St. Louis, USA), dehydrated, and mounted on the slides with Entellan medium (SigmaAldrich, St. Louis, USA). The slides stained with the $\mathrm{Bcl} 2$ anti-apoptotic marker were used to demonstrate germ cell viability. Positive reactions produced a sepia color (chromogenic substrate). The qualitative criteria for categorizing the immunohistochemical expression of $\mathrm{Bcl}-2$ were based on the parameters used for the determination of HER-2 scores in the HercepTest ${ }^{T M}$ kit (DAKO Corp., Carpinteria, CA). Table 1 shows the scores assigned to immunostaining.

\section{Statistical Analysis}

No statistical analysis was conducted. The results of histological and immunohistochemical evaluations were analyzed descriptively.

\section{RESULTS}

Rabbit number 2 (heterologous group) died four days before the biopsy for unknown reasons, and was excluded 
Table 1. $\mathrm{Bcl}-2$ staining scores

\begin{tabular}{|l|c|c|}
\hline Immunostaining standard & Score & Immunoreactivity \\
\hline Weak cytoplasmic or nuclear staining & $1+$ & Negative \\
\hline Strong cytoplasmic or nuclear staining & $2+$ & Mildly positive \\
\hline Strong nuclear and cytoplasmic staining & $3+$ & Strongly positive \\
\hline
\end{tabular}

from the study. The remaining 11 rabbits recovered from surgery uneventfully.

\section{Fresh Tissue And Solutions}

Histological analysis of the fresh biopsy specimens collected from the subjects revealed the presence of stroma and follicles in different stages of development, while immunohistochemistry showed strong $\mathrm{Bcl}-2$ staining $(3+)$, indicating that the rabbits were at reproductive age. Histology tests showed that the six solutions originating from the fresh germinal tissue of the odd-numbered rabbits contained a lower number of germ cells (stromal cells and follicles). Immunohistochemical assessment of all solutions also revealed decreased $\mathrm{Bcl}-2$ staining. While the score for fresh ovarian tissue was $3+$ (strongly positive), the score for the solutions was $2+$ (weakly positive). With the exception of solution 4 (rabbit 7), which obtained score $1+$ (negative), the other five solutions were deemed to contain viable germ cells (Figure 1 ).

\section{Transplanted Tissue}

Table 2 shows the histology and immunohistochemistry test results for transplanted tissue. Ovarian stroma was present in four ( $80 \%)$ of the five rabbits in the heterologous group, and in five $(83.3 \%)$ of the six rabbits in the homologous group. The two rabbits that had no ovarian stroma (rabbits 7 and 8 ) had been injected with solution 4. Follicular cells were present in three $(60.0 \%)$ of the five rabbits in the heterologous group, and in four (66.6\%) of six rabbits in the homologous group. Three rabbits in the heterologous group (rabbits 6, 10 and 12), and two in the homologous groups ( 9 and 11 ) had $2+$ scores in $\mathrm{Bcl}-2$ staining. One of the rabbits given a heterologous graft (rabbit 4), and three of the rabbits given homologous graft ( 1,3 and 5$)$, had $3+$ scores in $\mathrm{Bcl}-2$ staining. All rabbits $(100 \%)$ in the heterologous group, and only one subject (rabbit number 5 ) in the homologous group, had inflammatory cells in their excisional biopsy specimens (Figure 2).

\section{DISCUSSION}

This study compared heterologous to homologous transplantation of germ cells in the abdominal region of white New Zealand rabbits. To our knowledge, this is the first study to attempt the transplantation of germ cells from one animal to another (heterologous transplantation) without the use of immunosuppressants. The study demonstrated promising results, with the presence of stromal and follicular cells and the absence of apoptotic cells in both groups of subjects analyzed.

The enzymatic digestion of germinal tissue was performed to separate germ cells from the surrounding tissue in an attempt to eliminate the $\mathrm{MCH}$-II-positive cells found in connective tissue and minimize the effects of rejection. The injection of germ cells only (follicles and stroma) was expected to facilitate angiogenesis and neovascularization at the receptor site. Previous research showed that the outcomes of heterotopic or orthotopic transplantation of ovarian tissue in mice were significantly impaired when neovascularization did not occur within 48 hours of transplantation (Demeestere et al., 2009). The authors also showed that stromal integrity is essential for the process of neovascularization and survival of follicular tissue. Primordial follicles can withstand ischemia for four hours, but stromal cells surrounding follicles are more sensitive to ischemia than primordial follicles. This finding has been associated with dramatic decreases in transplanted tissue viability, which might undergo fibrosis (Demeestere et al., 2009).

To avoid ischemia-related issues, in the present study the solution containing germ cells was injected in the homologous and heterologous subjects during the same surgical session, about 75 minutes after the removal of the ovaries. The small size of the ovaries and the small amount of solution obtained required that homologous/ heterologous transplantations be carried out in pairs. The 60 days between transplantation and collection of biopsy specimens provided ample time not only to assess the viability of the implanted tissue, but also to look into the possible effects of transplantation on the health status of the subjects. Although one of the rabbits given a heterologous implant (rabbit 2) died just before biopsy for no apparent reason, all the other subjects recovered uneventfully.

The protocol used for the production of the solution containing germ cells was based on a previous study (Osterholzer et al., 1985). However, modifications were made in an attempt to minimize the possible damage caused to germ cells. A buffered medium (PBS) with a more stable $\mathrm{pH}$ was used to rinse the tissue and prepare the solutions. Germinal tissue specimens (before digestion) and germ cells (after digestion) underwent several rinsing steps to remove possible impurities and residual collagenase, respectively, which otherwise might have compromised our outcomes. Exposure time to collagenase was also decreased from 60 to 45 min to reduce the risk of damage to the follicles.

A recent study revealed that the ovarian extracellular matrix between the follicles can be digested by collagenase type 1 . However, the collagen present within the follicles can also be degraded and damage follicle integrity (He \& Toth, 2016). This could explain the fact that, although the ovarian tissue of rabbit 7 provided a follicle-rich germinal tissue specimen, the solution produced from this tissue (solution 4) had a negative score (1+) for Bcl-2 staining. This finding indicated that the follicles might have been damaged during digestion, and suggested that more studies should be performed before an ideal protocol is developed for the separation of ovarian germ cells.

As expected, inflammatory reaction was more commonly found in heterologous than in homologous grafts. Inflammatory cells were observed in only one subject given a homologous graft (rabbit 5), most likely due to trauma caused by the transplantation procedure. However, the inflammatory reaction observed in the present study was not so intense as to promote the death of germ cells, and no signs of rejection were observed in the transplanted tissue.

The design used in this study allowed, with a good degree of reliability, the production of tissue specimens containing germ cells. The use of a sterile marker injected with the solution made it possible. The findings, and 

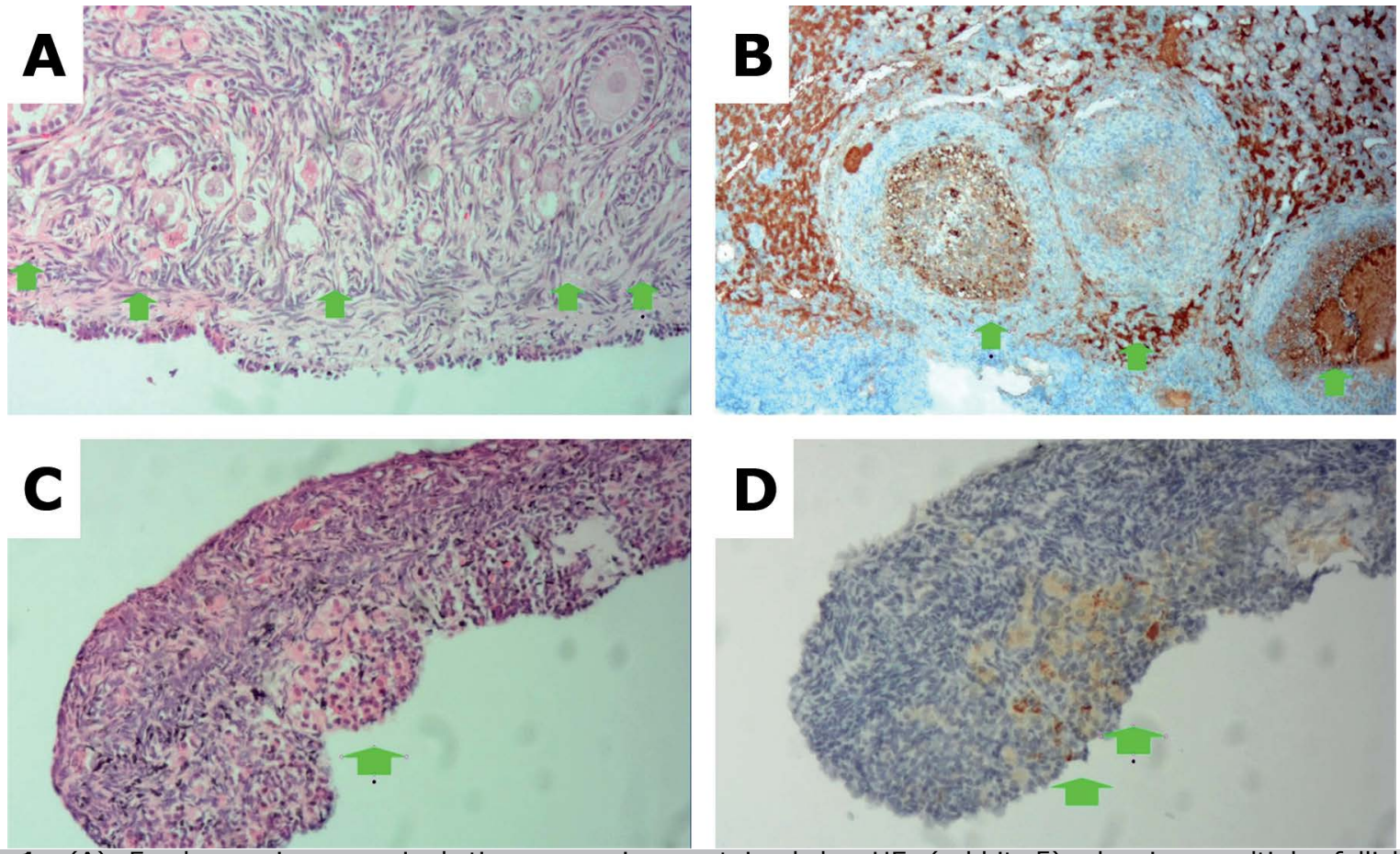

Figure 1. (A) Fresh ovarian germinal tissue specimen stained by HE (rabbit 5) showing multiple follicles. (B) Immunohistochemistry staining of fresh ovarian germinal tissue specimen showing several follicles (arrows) with strong $\mathrm{Bcl}-2$ staining in sepia color (3+). (C) HE-stained germ cell solution (solution 3 ) revealing the presence of ovarian tissue (elongated stromal cells) and the outline of a follicle (arrow). (D) Immunohistochemistry staining of germ cell solution with weak sepia $\mathrm{Bcl}-2$ staining $(2+)$.

Table 2. Comparison of heterologous and homologous transplantation groups for presence of ovarian stroma follicular cells, Bcl-2 marking, and inflammatory cells in the 11 rabbits evaluated

\begin{tabular}{|c|c|c|c|c|}
\hline \multirow{3}{*}{ Variables } & \multicolumn{4}{|c|}{ Groups } \\
\hline & \multicolumn{2}{|c|}{$\begin{array}{c}\text { HETEROLOGOUS } \\
(n=5)\end{array}$} & \multicolumn{2}{|c|}{$\begin{array}{c}\text { HOMOLOGOUS } \\
(n=6)\end{array}$} \\
\hline & $\mathbf{N}$ & $\%$ & $\mathbf{N}$ & $\%$ \\
\hline \multicolumn{5}{|c|}{ Ovarian stroma } \\
\hline Absent & 1 & 20 & 1 & 16.7 \\
\hline Present & 4 & 80 & 5 & 83.3 \\
\hline \multicolumn{5}{|c|}{ Follicular cells } \\
\hline Absent & 2 & 40 & 2 & 33.33 \\
\hline Present & 3 & 60 & 4 & 66.66 \\
\hline \multicolumn{5}{|c|}{ BCL2 marking } \\
\hline $1+$ & 1 & 20 & 1 & 16.7 \\
\hline $2+$ & 3 & 60 & 2 & 33.3 \\
\hline $3+$ & 1 & 20 & 3 & 50 \\
\hline \multicolumn{5}{|c|}{ Inflammatory cells } \\
\hline Absent & 0 & 0 & 5 & 83.3 \\
\hline Present & 5 & 100 & 1 & 16.7 \\
\hline
\end{tabular}

particularly the data from rabbits in the homologous graft group, seem to indicate that the marker had no impact on the outcomes. This method has been successfully used in previous animal studies, demonstrating the benefits of using the marker (Almodin et al., 2004, 2004).

The transplantation of germ cells was performed in a heterotopic site to facilitate tissue collection and analysis. However, this procedure carries some inherent limitations. It was recently reported that one of the main reasons for decreased graft viability is the unsuitability of the heterotopic environment for the neovascularization process, due to changes in temperature, pressure, lack of space for follicular growth, as well as the presence of cytokines, and angiogenic and hormonal factors.

Despite the preliminary nature of the results reported in this study, its encouraging findings support the organization of future studies on the development of solutions for selected POF patients. Orthotopic transplantation, associated with an adequate protocol for the isolation of ovarian germ cells, may offer more promising results. However, further research is required to better understand the antigenic factors involved in the transplantation of germ cells, and to establish an optimal ovarian germ cell separation protocol.

\section{CONCLUSIONS}

Given the conditions of the present study, heterologous and homologous transplantation of germ cells in rabbits had similar outcomes and were proven viable procedures. 

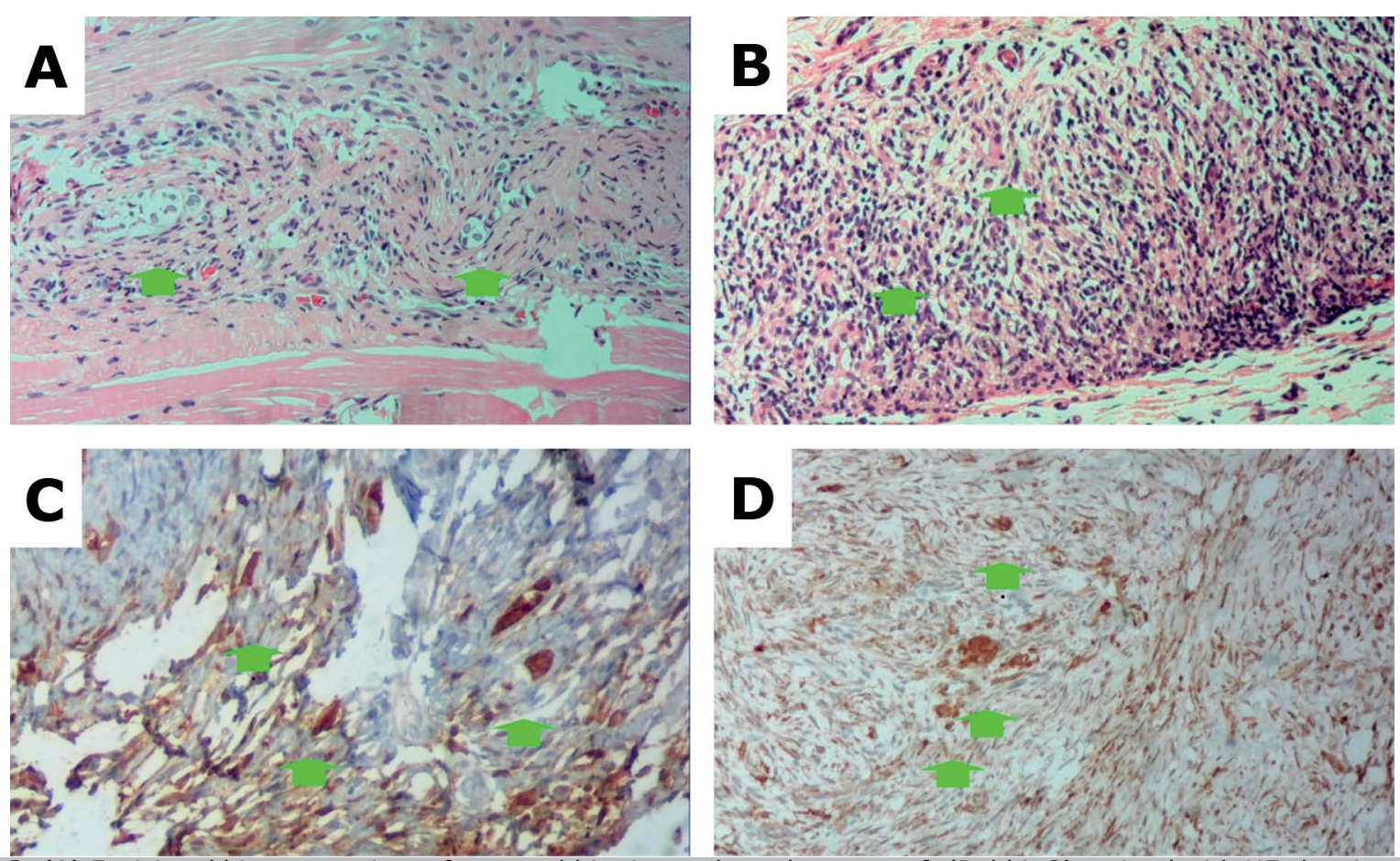

Figure 2. (A) Excisional biopsy specimen from a rabbit given a homologous graft (Rabbit 3) stained with HE showing ovarian tissue containing stroma and a few primordial follicles (arrows) among the soft tissue, absence of necrosis or inflammatory cells. (B) Excisional biopsy specimen from a rabbit given a heterologous graft (rabbit 4) stained with $\mathrm{HE}$, showing ovarian tissue containing stroma and a few primordial follicles among the soft tissue, absence of necrosis, and presence of inflammatory cells. (C) Excisional biopsy specimen from a rabbit given a homologous graft (rabbit 3) with Bcl-2 staining, showing strong sepia marking $(3+)$ in the cell cytoplasm. (D) Excisional biopsy specimen from a rabbit given a heterologous graft (rabbit 4) with $\mathrm{Bcl}-2$ staining showing strong marking $(3+)$ in sepia color in the cell cytoplasm.

\section{ACKNOWLEDGEMENTS}

The media used in this study was kindly supplied by Ingámed Materiais Médico-Hospitalares LTDA (Maringá, Brazil).

The authors would like to thank Mr. Antonio Carlos Correa for his support with the English version of the paper, and the staff with Materbaby Human Reproduction Clinic and the Surgery Department at Ingá University Center for their technical support during the procedures.

\section{CONFLICT OF INTERESTS}

This study was carried out without funding.

\section{Corresponding author:}

Paula M. A. Cerialle

Materbaby - Reprodução Humana e Genética,

Maringá - PR - Brazil

E-mail: paula_almodin@hotmail.com

\section{REFERENCES}

Almodin CG, Minguetti-Câmara VC, Meister H, Ceschin AP, KrigerE, Ferreira JO. Recovery of natural fertility after grafting of cryopreserved germinative tissue in ewes subjected to radiotherapy. FertilSteril. 2004a;81:160-4. PMID: 14711560 DOI: http://dx.doi.org/10.1016/j.fertnstert.2003.05.023

Almodin CG, Minguetti-Câmara VC, Meister $H$, Ferreira JO, Franco RL, Cavalcante AA, Radaelli MR, Bahls AS, Moron AF, Murta CG. Recovery of fertility after grafting of cryopreserved germinative tissue in female rabbits following radiotherapy. Hum Reprod. 2004b;19:1287-93. PMID: 15117903 DOI: 10.1093/humrep/deh246
AubardY, Newton H, SchefferG, Gosden R. Conservation of the follicular population in irradiated rats by the cryopreservation and orthotopic autografting of ovarian tissue. Eur J Obstet Gynecol Reprod Biol. 1998;79:83-7. PMID: 9643409 DOI: http://dx.doi.org/10.1016/S0301-2115(98)00044-X

Barua A, Yoshimura Y. Immunolocalization of MHC-II+ cells in the ovary of immature, young laying and old laying hens Gallus domesticus. J Reprod Fertil. 1999;116:385-9. PMID: 10615265 DOI: 10.1530/jrf.0.1160385

Bhavnani BR, Stanczyk FZ. Pharmacology of conjugated equine estrogens: efficacy, safety and mechanism of action. J Steroid Biochem Mol Biol. 2014;142:16-29. PMID: 24176763 DOI: 10.1016/j.jsbmb.2013.10.011

Cobo A, Garrido N, Pellicer A, Remohí J. Six years' experience in ovum donation using vitrified oocytes: report of cumulative outcomes, impact of storage time, and development of a predictive model for oocyte survival rate. Fertil Steril. 2015;104:1426-34.e1-8. PMID: 26353081 DOI: $10.1016 /$ j.fertnstert.2015.08.020

De Vos M, Devroey P, Fauser BC. Primary ovarian insufficiency. Lancet. 2010;376:911-21. PMID: 20708256 DOI: $10.1016 /$ S0140-6736(10)60355-8

Demeestere I, Simon P, Emiliani S, Delbaere A, Englert Y. Fertility preservation: successful transplantation of cryopreserved ovarian tissue in a young patient previously treated for Hodgkin's disease. Oncologist. 2007; 12:1437-42. PMID: 18165621 DOI: $10.1634 /$ theoncologist.12-12-1437 
Demeestere I, Simon P, Emiliani S, Delbaere A, Englert Y. Orthotopic and heterotopic ovarian tissue transplantation. Hum Reprod Update. 2009;15:649-65. PMID: 19474206 DOI: $10.1093 /$ humupd/dmp021

Donnez J, Dolmans MM, Demylle D, Jadoul P, Pirard C, Squifflet J, Martinez-Madrid $B$, van Langendonckt A. Live birth after orthotopic transplantation of cryopreserved ovarian tissue. Lancet. 2004;364:1405-10. PMID: 15488215 DOI: $10.1016 / S 0140-6736(04) 17222-X$

Donnez J, Dolmans MM, Pellicer A, Diaz-Garcia C, Sanchez Serrano M, Schmidt KT, Ernst E, Luyckx V, Andersen $\mathrm{CY}$. Restoration of ovarian activity and pregnancy after transplantation of cryopreserved ovarian tissue: a review of 60 cases of reimplantation. Fertil Steril. 2013;99:1503-13. PMID: 23635349 DOI: 10.1016/j.fertnstert.2013.03.030

Gaowa S, Sun AJ, Jiang Y, He FW, Zheng TP, Wang YP. Ultrasonographic observation of the breast in early postmenopausal women during therapy with Cimicifuga foetida extract and sequential therapy with estrogen and progestin. Chin Med J (Engl). 2015;128:1000-4. PMID: 25881590 DOI: $10.4103 / 0366-6999.155052$

He $X$, Toth TL. In vitro culture of ovarian follicles from Peromyscus. Semin Cell Dev Biol. 2016;61:1409. PMID: 27397871 [Available on 2018-01-01] DOI: $10.1016 /$ j.semcdb.2016.07.006
Osterholzer HO, Streibel EJ, Nicosia SV. Growth effects of protein hormones on cultured rabbit ovarian surface epithelial cells. Biol Reprod. 1985;33:247-58. PMID: 3933584

Pinto Marín A, Ballesteros García AI, Izarzugaza Perón Y, Mansó Sánchez L, López-Tarruella Cobo S, Zamora Auñón P. Adjuvant hormonal therapy in perimenopausal patients. Adv Ther. 2011;28 Suppl 6:39-49. PMID: 21922394 DOI: $10.1007 / \mathrm{s} 12325-011-0023-3$

Silber SJ, DeRosa M, Pineda J, Lenahan K, Grenia D, Gorman K, Gosden RG. A series of monozygotic twins discordant for ovarian failure: ovary transplantation (cortical versus microvascular) and cryopreservation. Hum Reprod. 2008;23:1531-7. PMID: 18285322 DOI: $10.1093 /$ humrep/den032

Wolff EF, He Y, Black DM, Brinton EA, Budoff MJ, Cedars MI, Hodis HN, Lobo RA, Manson JE, Merriam GR, Miller VM, Naftolin F, Pal L, Santoro N, Zhang H, Harman SM, Taylor HS. Self-reported menopausal symptoms, coronary artery calcification, and carotid intima-media thickness in recently menopausal women screened for the Kronos early estrogen prevention study (KEEPS). Fertil Steril. 2013;99:1385-91. PMID: 23312232 DOI: 10.1016/j.fertnstert.2012.11.053 